\title{
Research on the Design for Hotel Room
}

\author{
Yingfeng Kuang \\ South China university of Technology \\ Guangzhou, China 510000
}

\author{
Weihai Zhang* \\ South China university of Technology \\ Guangzhou, China 510000 \\ *Corresponding Author
}

\begin{abstract}
Thanks to the rapid economic development, nowadays more and more people are willing go out for a journey. Therefore, hotel rooms have become a necessity for traveling, which has boosted the development of hotels. So as a result, now people are very careful about choosing hotels. The factors for their choice are varied, such as environment, appearance, service and so forth. In this article, we will analyze the current situation of the design for hotels and some problems behind it. Also for those problems, we wills redesign it from three different aspects, function redesign, style redesign and humanization redesign, hoping to better the current situation and develop the design for hotels.
\end{abstract}

Keywords-the design for hotels; innovation of design; the culture of hotel

\section{INTRODUCTION}

In this article, we will see the design for hotel room as a system and divide the design into three parts, function design, style design and humanization design. In addition, we stressed the importance of color harmony for design in order to make the guestrooms more elegant and comfortable. Also in this article we consider the local culture as an important factor for design, which can result in a very special and suitable design rather than the dull and lifeless one before. In the end of the article we solved the current problems of guestrooms and make it out of the constraint of traditional hotels by redesigning them, trying to make the environment comfortable and inviting.

\section{RESUME OF HOTEL ROOM}

\section{A. The Origin of Hotel}

In ancient china, hotel is the place that provides food and beds for travelers. While in the past there's no hotel in European countries. Travelers can stay in castles, pubs, monasteries, churches or farms on their way. As time goes by, they developed into the hotels now we see. Also because of the demand for better living quality, hotels have made many innovations on functions.

Hotel is a space affording accommodation, food and other services based on a building. Hotel is also an economic entity that gains profit by providing those services. As a part of the service industry, hotel must satisfy its guests, for example by providing neat accommodations and delicious food.

\section{B. Current Situation of Hotels}

Nowadays hotel industry is in a period of rapid development. And different hotels are in a fierce competition. While a special style of the design for hotel room can enhance the hotel's competitiveness and let the hotel stand out Therefore, the style of design has become a focus.

Hotel is a public building providing accommodations and food for travelers. Hotels can be divided into tourist hotel, business hotel, conference hotel, entertainment hotel, sports hotel, and sanatorium and so on. A hotel consists of a living area, a public area, an administration area and power area. Some big hotels also have an individual food area.

Hotel rooms absolutely take an important part of all the businesses. It is one of the major incomes for hotels so the occupancy rate can directly influence a hotel's performance. To raise the occupancy rate, the style of the design for hotel room must satisfy the guests. The hotel industry has become one of the most competitive industries especially in some famous cities with many tourist attractions. So how to improve the comfort and elegance of hotel room is becoming vital. With more choice, people will absolutely choose the hotel with a more pleasant and more elegant guestroom.

According to a survey, almost every guestroom's design mode is identical. That is the result of copy and so people are familiar with the same mode and they don't have to pay attention to it when choosing a hotel. But people are becoming more and more bored with the dull and same design for every different hotel room.

For now, the layouts of most hotel rooms are almost the same. This phenomenon has impacted a lot of people, including the investors, operators and to some extent, the guests. Everybody lives in rooms with the same layout and design will only let people develop the same visual habit.

\section{THE ART AND TECHNIQUE OF DESIGNING GUESTROOM FOR HOTEL}

\section{A. Color Coordination}

How to coordinate color in an interior space is an unavoidable issue when designing a hotel room. That is also a crucial factor to achieve an aesthetic appearance. Now most of the rooms' interior colors are dull and lifeless, not because other colors are not appropriate, but because of the current copying situation. Hotels seem fearing to change the 
current color match and that makes hotel rooms' colors all the same.

When it comes to color match, only if we are dare to innovate, we are able to create many different color match in hotel rooms. For costumers, they are looking forward to see more different styles and more innovated color match, which as a result will create more and more special hotels. And when hotels create the demand, more and more costumers will enjoy living in different hotels.

\section{B. Materials' Match}

People pay very much attention to the comfort and beauty of a guestroom. The sense of comfort and elegance is decided by materials themselves and the way how they match. So we can see how important it is for a hotel to choose the right materials.

The designer is decisive for that. Through the project design we can directly see whether the room is elegant and comfortable or not. Of course, designers also need to match materials with the interior space. For instance, furniture should be placed appropriately, leaving enough space for activity. Furniture also should be designed to make room for public space. In the restroom, rather than repeat the layout as before, designers should arrange sanitary ware differently to make a brand new look for the restrooms.

\section{Style Design}

Style design can be an objective way to reflect whether the design of the rooms is good or not, guests will choose their own room based on the style of the room. So style design is essential for designing hotel rooms. But now hotel rooms' style design is almost identical without innovation, making the passengers easy to have aesthetic fatigue. We believe that there should be more innovative factors in style design, so as to attract more travelers to come.

We cannot underestimate the significance of the style design for hotel rooms. Actually style design can guide people on choosing hotels, innovative and interesting style design can be more attractive to people. Designing a different style for the hotel room is also an innovative behavior.

The style design for a hotel room also represents the cultural orientation of that hotel, and that style may also become the characteristics of this hotel culture in return. How a hotel will develop in the future largely depends on whether the style design is good or bad and whether the design is reasonable, appropriate and beautiful.

\section{Functional Design}

Functional design is on the first row for interior design. Functional design is also very important when designing hotel rooms. We must take the functionality of those rooms and what it can bring to travelers into account. Once there are some flaws in a room's function, its life span will be very short no matter how prominent it is in style design or humanized design.

\section{E. Humanized Design}

In addition to style design and functional design, there is another very important and indispensable part of design, humanized design. At present, some hotels maybe very delicate in terms of functional design and style design, but only lack of humanized design. Now the situation is that expensive and luxury materials cover up the consumer's true care. It distracted consumers' attention and hided the real humanized design. However, we believe that with the advancing of our society and the change of age, this impetuousness will be gradually replaced by more humanized design and is bound to become the main direction for star hotels' dynamic design.

\section{Hotel RoOm Culture Design}

\section{A. Traditional Culture}

People living in a certain region are nourished with their own traditional culture. For designers, we can add some traditional culture's elements into our design so that the room will be more unique and pleasant with a sense of belonging. By doing so, the room will also be simpler and more beautiful. Of course, in addition to the elements of the local culture, traditional culture can also be combined with the design. This design style will not only have a better cultural atmosphere, but also makes the room looks more beautiful. Now this kind of room is relatively rare, which makes this kind of room more welcoming than other style rooms. Moreover, because this room has a traditional local culture atmosphere, while resting in the room, travelers can also appreciate and understand the local traditional culture at the same time, which can be described as killing two birds with one stone.

\section{B. Foreign Culture}

In addition to the traditional culture, guestroom design can also be considered with the combination of foreign culture, which may also be an innovation, such as Valentine's Day, Christmas and so forth. In this way, we may achieve unexpected results, which may give a surprise to costumers. The combination of foreign culture and room design can also let people learn more about foreign culture, which can attract more travelers to come to stay.

\section{The Design and Culture of Hotel Room}

Hotel room is generally a "cultural product" with a combination of cultural elements and excellent technology. It needs a good function and artistic appearance. While designing with the principle of humanization and some local cultural elements can add some specialty and unique feelings to the hotel room.

Room design style is not immutable. A different design style can be created simply by adding a little modified color or a new color match. For now, almost no one has changed color for hotel room's interior design, which leads to the fact that the hotel rooms are almost identical in color. But if they are able to incorporate some cultural elements into the design 
to create a new style, customers will be surprised and more travelers may come to stay.

\section{CONCLUSION}

Currently many operators still can't get rid of the fixed mode, which made most of the design for hotel rooms keep copying from each other.

Based on the theory and research, this article tries to find the existing problems of the design for hotel rooms, as well as its lacks and defects in functional design, style design and humanized design. Moreover, we discussed about the color match for hotel room design. And by applying research and theories to reality, we try to improve these issues, proposed solutions and finally test our solutions. By doing so we hope we can promote the overall level of the design for hotel rooms. Hoping that when this research comes out, we can greatly reduce the identical design for hotel rooms' structure and style. We believe that this hotel room design study will also change the style of the room into a diverse era and avoid copy while also encourage more innovations.

To be honest, the most essential factor for the change of design is the attention from investors and operators. Only when they noticed the significance of this issue can the design for hotel rooms develops. And only after understanding and absorb all kinds of design can we designers create something truly pleasant and special.

\section{REFERENCES}

[1] Zeng Guoojun, Zhao Yongqiu. the coordination of the authenticity and standardization for hotel design.[J]. Tourism Tribune.2013.

[2] li Peng, Huang Jihua, Mo Yanfen, Yang Guihua. Calculation and Analysis of Carbon Footprint for a Four-star Hotel in Kunming[J]. Tourism Tribune.2010.

[3] Zhang Ming. About the relationship between hotel design and brand administration.[J]. commercial age, 2010 .

[4] $\mathrm{Hu}$ Sixiao. Introduction to the trend of architecture design for American seniors.[J]. Architectural journal,2009.

[5] Cai Xiaomei. Business customers' Demand for hotel and Its Application in Hotel Planning and Design.[J]. Tourism science,2005.

[6] Wang Yi. Jiuzhaigou Valley International hotel — A design considering the local culture.[J]. Architectural journal.2004. 